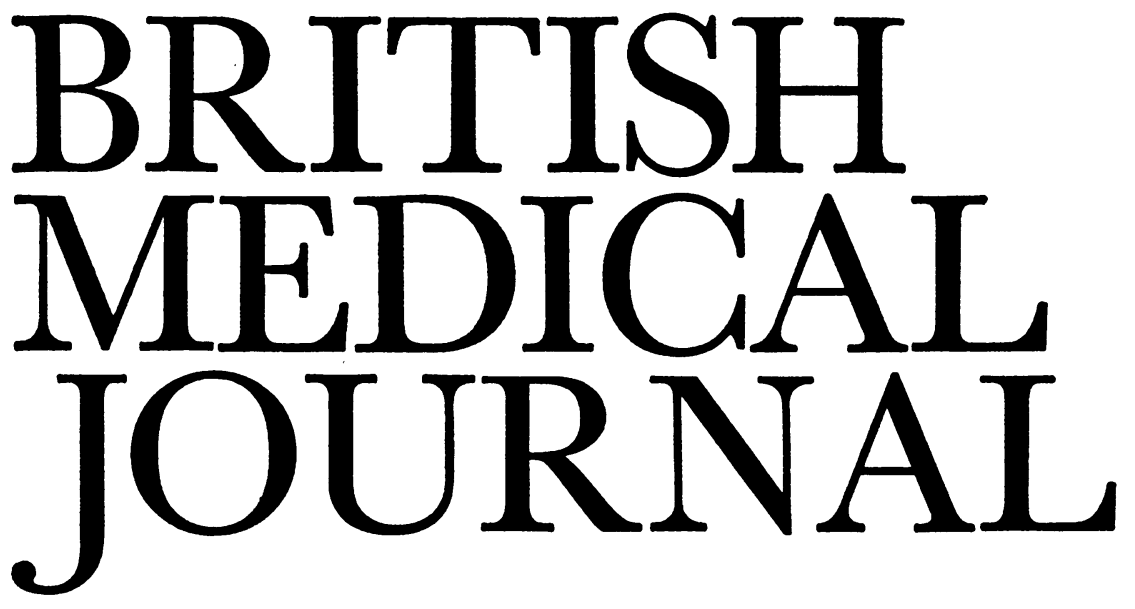

\title{
Working for Health
}

"No-work is a dangerous occupation". This and other aphorisms on the same theme point to the harm that comes from unemployment, whether it results from losing a job or is a part of what has come to be known as "institutional neurosis", also described as "institutionalism". Any segregated community is an unnatural social organization and can bring about institutionalism. When the segregation is great as in prisons and perhaps some mental hospitals, particularly those caring for mentally defective patients, the dire effects are prominent. The staff of such institutions, because of their absolute authority, may dictate both the nature and the extent of the work permitted and can therefore control the degree to which the people in their charge can be perhaps unwittingly degraded, demoralized, and dehumanized.

Patients in mental hospitals may be subject to a twopronged attack. One is from the pathological process inherent in the disease that afflicts them, as seen particularly in schizophrenics. The other results from possible adverse influences in the environment that surrounds them. It is doubtful even with our modern drugs if the first of the two can be materially modified, but equally there is no doubt that the second is susceptible to considerable modification. The pioneers of "moral treatment" in our mental hospitals in the nineteenth century appreciated fully the importance of the environment and in particular the therapeutic value of work. John Conolly, 1 that great visionary and reformer, wrote in 1847: "Among the means of relieving patients from the monotony of an asylum, and of preserving the bodily health, and, at the same time, of improving the condition of the mind, and promoting recovery, employment of some kind or other ranks the highest". Across the Atlantic, John Minson Galt II, superintendent of the Eastern State (Mental) Hospital in Williamsburg, Virginia, advocated the same approach, and he reported in 1842 that of his 125 patients all but 20 who were too old or sick were occupied. He gave a long list of the varieties of work available to both men and women in his hospital. All of it, he insisted, was carried out primarily in the interests of treatment and only secondarily for the economic benefit of the hospital.

As with so many reforms, the impulse generated by the reformers in their lifetime spent itself. So it was that not long after the death of Conolly a pall of apathy and inertia settled over the mental hospitals in England. The atmosphere became restrictive, and for the majority of the patients to allow them to do nothing was a matter of deliberate policy. And yet at all times there were the privileged few, mainly quiescent chronic schizophrenics and relatively high-grade patients of subnormal intellect, who gave invaluable help in the utility departments and the various undertakings on which the community depended. Indeed, without the patient's labour it would probably have been impossible to run the farms which were a common feature of the hospitals in those days or to maintain the elaborate grounds and gardens.

About the time of the second world war there was a swing back towards the principles of moral treatment. Dignity and self-respect were restored to the patients in terms of personal possessions and civilized clothing, and the right to work was restored to them mainly through the medium of occupational therapy. Industrial therapy came later. The ideal in that was to encourage patients to work in a situation simulating as closely as possible that common in industry outside the hospital, and they received the stimulus of being paid for their labours. But to be realistic industrial therapy must be economically viable and the rates of pay have to be kept at a minimum. Even so, there have always been, and will always be, a number of patients, mainly women, who understandably will eschew industrial work and prefer to do domestic work, even though the "rewards" may be nominal. There can be few hospitals, if any, in which the patients do not make some contribution, great or small, in the form of cleaning, making beds, setting tables, assisting their even less fortunate brethren, and helping in a myriad other ways towards the common good. These altruistic helpers need little or no direction or coercion. They work because they enjoy what they do, and by so doing they fulfil a fundamental need in all of us-to be needed.

With so much varied work going on, for which payment is somewhat arbitrary, it is easy to see how thin at times is the line separating occupation and exploitation, or, to revert to Dr. Galt, how well-nigh impossible it becomes to differentiate exactly between what is primarily of therapeutic benefit and what is secondarily of economic benefit to the hospital. It is precisely this dilemma which has sparked off the most recent accusations of ill-treatment 
of patients in the lay press. In a hospital for mentally subnormal patients in the Birmingham area, it is all zged, "patients were being exploited by being used as nurses and domestic staff". ${ }^{3}$ There are times, it would seem, when the administrators of mental hospitals just can't win.

1 Conolly, J., The Construction and Government of Lunatic Asylums and Hospitals for the Insane. Introduction by Richard Hunter and Ida Macalpine. First published 1847. London, Dawsons of Pall Mall, 1968.

2 Dain, N., Disordered Minds: The First Century of Eastern State Hospital in Williamsburg, Virginia, 1766-1866. Williamsburg, Virginia, Colonial Williamsburg Foundation, 1971.

3 The Times, 26 August 1971.

\section{Coronary Deaths}

In 1948 a long-term prospective study of cardiovascular disease was begun in the town of Framingham, Massachussetts. A sample of 2,336 men and 2,873 women between the ages of 29 and 62 years was selected for study from a total population of 30,000 inhabitants. They were examined and investigated, and their blood pressures, smoking habits, body weights, serum cholesterols, electrocardiograms, and other details noted. And they were observed twice a year so that the relationship between these data and subsequent coronary artery disease could be discovered. The first fruits of this epidemiological survey were the finding that men with low blood cholesterols and normal blood pressures, and who did not smoke, had one-third of the standard risk of developing coronary heart disease, while if all these factors were adverse the risk increased tenfold. ${ }^{1}$ A mass of information collected over 20 years on the epidemiology of coronary artery disease was published last year. ${ }^{2}$

A more recent report has now appeared on the death of persons less than 65 years of age from coronary artery disease. ${ }^{3}$ The report is on 102 men and 18 women. Twothirds of these deaths were unexpected and took place outside hospital; more than one-half were sudden, occurring within one hour of the onset of the first symptom. Death was more likely to be sudden in younger than older individuals and in men than women. Two-thirds of the sudden coronary deaths occurred in people without previous clinical or electrocardiographic evidence of coronary artery disease. This is specially notable, because owing to the repeated routine cardiovascular examinations of this group of persons much more was known of their cardiovascular status than is usual in a general population, and minor findings had a greater chance of being kept under observation for possible progression.

This study also follows the fate of those who survive an acute myocardial infarct. Nine out of 10 returned to work, but there was a high rate of recurrence. Indeed $41 \%$ had a further attack within six years and one-half of these recurrences were fatal. In an earlier study L. Kuller and his colleagues ${ }^{4}$ investigated the natural history of the arteriosclerotic heart disease in Baltimore residents aged 40 to 64 years who died of it. In the 610 deaths examined about one-fifth of the persons were found dead, one-half died within two hours of the onset of the attack, and two-thirds within 24 hours.

Coronary artery disease is common. Population studies have shown that it is the cause of death in 4 out of 10 men and 2 out of 10 women. ${ }^{5}$ The incidence is rising. ${ }^{6}$ It frequently attacks without warning and often causes death within an hour of the first symptom. As a majority of such deaths occur outside the hospital, intensive care can help only a minority. It is difficult to see how the mortality can be reduced except by preventive measures. Salvage of survivors from myocardial infarction can do little to reduce the total mortality.

In countries with the highest incidence of coronary artery disease there is a disturbing trend of increasing mortality. Among men in Britain the mortality rose $35 \%$ in the age group 45 to 54 years, and $50 \%$ in the age group 35 to 44 years, between the years of 1955 and $1964 .{ }^{6}$ Increased attention must be directed to epidemiology and prevention. A study of 300 American soldiers with an average age of 22.1 years killed in the Korean war showed that in $12.3 \%$ one or more of the main coronary arteries was narrowed by atheroma to half or less of the original lumen. ${ }^{7}$ Similar evidence of advanced atheroma at an early age has been collected from accidental deaths in Great Britain. ${ }^{8}$ The liability to clinical coronary artery disease depends to a large extent on the complication of thrombotic occlusion.

Of the available preventive measures against clinical coronary artery disease, only stopping smoking has so far been shown to reduce the incidence of further myocardial ischaemic attacks.9 Furthermore, the greater liability to coronary artery disease associated with cigarette smoking is an acute risk, for stopping smoking promptly reduces the liability to that of non-smokers. ${ }^{10}$ No proof has yet been advanced that lowering the serum cholesterol, treating hypertension, reducing obesity, or encouraging physical activity improves the prognosis of survivors from an initial coronary artery attack.9 These facts should give further impetus to the Government efforts to discourage smoking, for they point to at least one way of diminishing a disease which the World Health Organization ${ }^{11}$ has described as "potentially the greatest epidemic mankind has faced."

1 Dawber, T. R., Kannel, W. B., Revotskie, N., and Kagan, A., Proceedings of the Royal Society of Medicine, 1962, 55, 265

2 Gordon, T., and Kannel, W. B., in The Community as an Epidemiological Laboratory, ed. I. I. Kessler and M. L. Levin, p. 123. Baltimore, John Hopkins Press, 1970.

- Gordon, T., and Kannel, W. B., fournal of the American Medical Association, 1971, 215, 1617 .

- Kuller, L., Lilienfeld, A., and Fisher, R., Circulation, 1966, 34, 1056.

5 Spiekerman, R. E., Brandenberg, J. T., Achor, R. W. P., and Edwards,

- Oliver, M. F., in Modern Trends in Cardiology, 2, ed. A. M. Jones, p. 46. London, Butterworth, 1969.

' Enos, W. F., Holmes, R. H., and Beyer, J., fournal of the American Medical Association, 1953, 152, 1090.

- Mason, J. K., British Medical fournal, 1963, 2, 1234

- Mason, J. K., British Medical Fournal, 1963, 2, 1234

10 Doyle, J. T., Dritish Heart fournal, 1970, 32, 583. Doyle, J. T., Dawber, T. R., Kannel, W. B., Kinch, S. H., and Kah
H. A., fournal of the American Medical Association, 1964, 190, 886. 11 World Health Organization, Bulletin of the International Society of Cardiology, 1969, 1, 1.

\section{International Voice}

The need for an organization to give the medical profession an international voice is certainly as great today as when the World Medical Association was founded in 1947. State control of medicine is almost everywhere increasing, and if the benefits it offers of fairer distribution are not to be destroyed by a fall in professional standards the profession itself must be able to speak out effectively. To support a member association when a government threatens these standards is a task that might fall to the W.M.A. At the same time it has a function in helping to formulate the 